\title{
Carbohydrates Impact in Type 2 Diabetes in Cats
}

\author{
Adrian Maximilian MACRI *, Alexandra SUCIU and Andrei Radu SZAKACS \\ Department of Animal Nutrition, Faculty of Veterinary Medicine, University of Agricultural Science and \\ Veterinary Medicine, Calea Mănăștur, nr.3-5, 400372 Cluj-Napoca, Romania \\ *corresponding author: adimacri@yahoo.com
}

Bulletin UASVM Veterinary Medicine 74(2)/2017

Print ISSN 1843-5270; Electronic ISSN 1843-5378

doi:10.15835/buasvmen-vm:0031

\begin{abstract}
Diabetes is one of the most commonly diagnosed endocrine diseases in cats. Of all types of diabetes, type II is the most frequent one, $80 \%$ of the diabetic cats have type II diabetes. Even though it's a multifactorial disease, obesity was found to be the most important risk factor in developing diabetes, obesity increases the chances of developing this disease to up to 4 times. The study was conducted on a number of 9 cats with uncomplicated diabetes with the purpose of monitoring the effects of the commercial dry food (with a high percentage of carbohydrates) and the commercial canned food (with a higher percentage of proteins and a lower percentage of carbohydrates) on the glycemic index. For this study, we considered the occasional administration of raw chicken and turkey meat because it wasn't given for a long enough period of time. The diet is very important for diabetic cats because a lot of sick cats enter remission after a couple of months of being fed wet canned food and they no longer need the administration of insulin, but owners are instructed to carefully monitor glycaemia for the rest of the pet's life.
\end{abstract}

Key words: cats, diabetes, insulin, diet.

\section{INTRODUCTION}

Diabetes (mellitus) is one of the most commonly diagnosed endocrinopathies in dogs and cats and classifies in four major categories (Rand et al., 2004):

Type I diabetes is specific to dogs and is characterized by hypoinsulinemia (Couto et al., 2014). A marker of the disease is represented by the presence of circulating autoantibodies: autoantibodies to islet cells, insulin autoantibodies or autoantibodies of enzymes involved in carbohydrate metabolism (Rijnberk et al., 2010).

Type II diabetes is predominant in cats (Couto et al., 2014), based on histological findings and clinical signs, about $80-95 \%$ of the diagnosed cats suffer from type 2 diabetes (Rand et al., 2004). It is characterized by insulin resistance and $\beta$-cells dysfunction (Rijnberk et al., 2010).

In the third category there are included "other types of diabetes" (Rand et al., 2004), i.e. diabetes secondary to different pathologies: pancreatitis, pancreatic carcinoma, hyper-somatotropism, hyperthyroidism or subsequent to glucocorticoids and progestin (Rijnberk et al., 2010).

The fourth category includes gestational diabetes in humans, but in dogs and cats this has not been reported. Diabetes associated with diarrhea in dogs may be considered, however, its equivalent (Rand et al., 2004). Diabetes mellitus encountered in cats resembles to type II diabetes encountered in humans in several aspects, including clinical, physiological and pathological signs of the disease (Henson et al., 2006). For example, the typical cat encountered with type II diabetes is obese and middle-aged and has low insulin levels. However, the main common feature is the appearance of amyloid IA (islet amyloid) in almost all cats with diabetes and in $90 \%$ of cases in humans (O'Brien, 2002). The classic symptoms presented by diabetic cats are polyuria, polydipsia, polyphagia accompanied by weight loss (Rijnberk et al., 2010). These may be accompanied by lethargy, lack of 
grooming behavior and the appearance of dry, scratchy and unhealthy fur. Cats may also show weakness in the hind limbs, decreased ability to jump or adopting the plantigrade position (Couto et al., 2014).

Factors that may lead to diabetes are: age, sterilization, gender and obesity (Hoenig, 2002). Although diabetes can occur at any age, the average age diagnosed is 10 years old (Couto et al., 2014). Sterilized cats have twice as much chance of developing diabetes and 1.5-fold more in tomcats (Hoenig, 2002). Obesity and lack of activity are the main causes that lead to insulin resistance and thus to the development of type II diabetes (Öhlund et al., 2017). Obesity and associated pathologies underlie metabolic diseases, including diabetes. Due to abnormal cytokine production, to acute phase reactants and to inflammatory pathway activation, obesity is associated with a chronic under-inflammation condition and appears to have a direct implication in insulin resistance, but the mechanisms by which it works are not perfectly elucidated (Wellen et al., 2003). It appears that regulating carbohydrate metabolism in tissues, such as muscle and fat, is an important factor in sensitivity to insulin.

Obesity, which is associated with reversible insulin resistance, affects the secretion and the action of insulin either by alterations to insulin receptors or by alterations to post-receptor processes (Rotlewicz et al., 2010). Even the fat tissue build-up pattern affects the severity of insulin resistance. In humans, abdominal obesity is more often associated with insulin resistance than peripheral obesity (Rand et al., 2004). Burmese cats are considered to be the most susceptible race to diabetes (Rucinsky et al., 2010), accumulating fat in the abdominal area, unlike other races that accumulate subcutaneous fat in the groin area (Rand et al., 2004).

Dietary opinions regarding diabetic animals have changed over the last few years (Rijnberk et al., 2010). Until recently, there have been applied recommendations from human medicine, which contain a diet rich in complex fibers and carbohydrates (Nelson, 1992), now the domestic cat is recognized as a true carnivore, metabolically adapted to primarily use protein and fat, and carbohydrate-rich diets appear to be unfavorable (Rijnberk et al., 2010). Thus, the traditional recommendation is contested by the hypothesis that continued intake of high amounts of carbohydrates promotes obesity and overloads pancreatic $\beta$-cells (Rand et al., 2004), and high protein and low carbohydrate diets may be beneficial to diabetes management (Frank and contributors, 2001).

\section{MATERIALS AND METHODS}

In this study, we followed how glycaemia of diabetic cats is influenced by diet, especially the carbohydrate content of the administrated food. The study was conducted between 2015 and 2017 at the Nutrition Department of the Faculty of Veterinary Medicine in Cluj-Napoca in collaboration with a veterinary clinic in ClujNapoca, two veterinary cabinets in Oradea and a veterinarian from Oşorhei, Bihor County. The collaboration was primarily with cat owners, keeping in touch with them via email, and having access to cats tracking through Google Docs.

Nine cats entered the casuistic: six sterilized males, two sterilized females, and a non-sterilized male. Of the nine cats, six have uncomplicated diabetes and did not show any major pathology before or after diagnosis, a cat developed iris melanoma 2 months after diagnosis of diabetes and two cats were also diagnosed with pancreatitis; one of them two years before the diagnosis of diabetes, and in the case of the other the diagnosis were put concomitantly. The latter was also diagnosed with chronic renal failure prior to the diagnosis of diabetes.

In the diagnosis of cats an important share was the anamnesis, the great majority of the owners observing polydipsia, polyuria and polyphagia with weight loss. Venous blood was collected from the jugular vein (to avoid blood clotting) with non-sedated cats, except for a sedentary cat. Biochemical analyses (ARKRAY- Spotchem ez sp 4430 Chemistry Analyzer) were performed for renal, hepatic and glucose monitoring or equal to or more than $300 \mathrm{mg} / \mathrm{dl}$, in the sphere of diabetes. Urinary analyses were performed with urine bands (PocketChem UA PU-4010, Arkray strips) and microscopic examination of sediment on urine collected by the owners. Glucose occurs in urine at blood glucose levels around $300 \mathrm{mg} /$ dl.

Because of the fact that in cats, blood glucose increases greatly in stressful situations, such as the visit to the veterinarian, the best monitoring is 
done in a familiar environment by people known to cats. Recommended method: when the cat is relaxed, the ear should be warmed (avoiding the use of alcoholic alcohol due to the strong door that can agitate the cat) for vasodilatation, then punctured until a drop of blood develops. This drop is absorbed on the meter's test strip. Glucose should be tested as often as possible and at least twice a day before insulin is given to avoid hypoglycemia or to adjust the insulin dose.

For the most complete monitoring of the cats, spreadsheets have been used in the Excel program, which looks at: blood sugar, insulin dose, type of cat food, and cat behavior. The first line is color coded and shows blood glucose. The desired glycaemia is represented by dark green, but the blue blood glucose is also acceptable: if the two spreadsheet predominates $\rightarrow$ good glycemic control; one day begins with AMPS hour: morning glucose before insulin; $+1,+2$ etc. signifies an hour after insulin, two hours after insulin, and so on up to +11 , when glucose can be tested; PMPS: blood glucose is checked the evening before the second dose of insulin; after the last column, next to each line, there is room for details such as cat food and behavior (Fig.1).

\section{RESULTS AND DISSCUSION}

of the nine cats enrolled in the study, four entered the remission, three had a stable glycaemic curve with low blood glucose, and two had irregular glucose. All the four cats that entered the remission did so only after they went to a low-carbohydrate diet. As Marshall et al. said in their study of 2009, the chances of getting into remission are greater with Lantus insulin, which is confirmed by 3 of the cases in the study that are in remission.

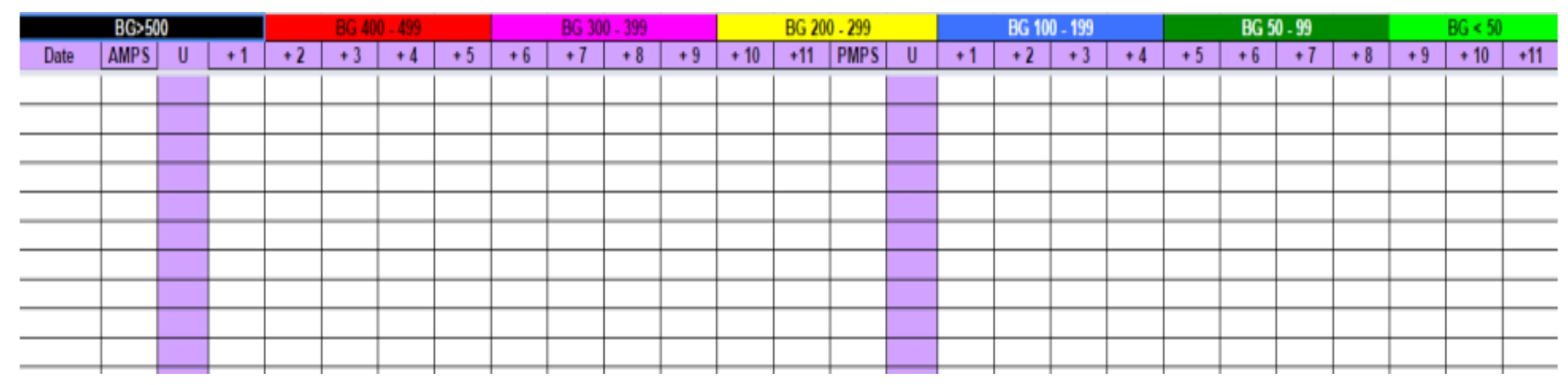

Fig. 1. Monitoring spreadsheet of feline diabetes (www.felinediabetes.com)

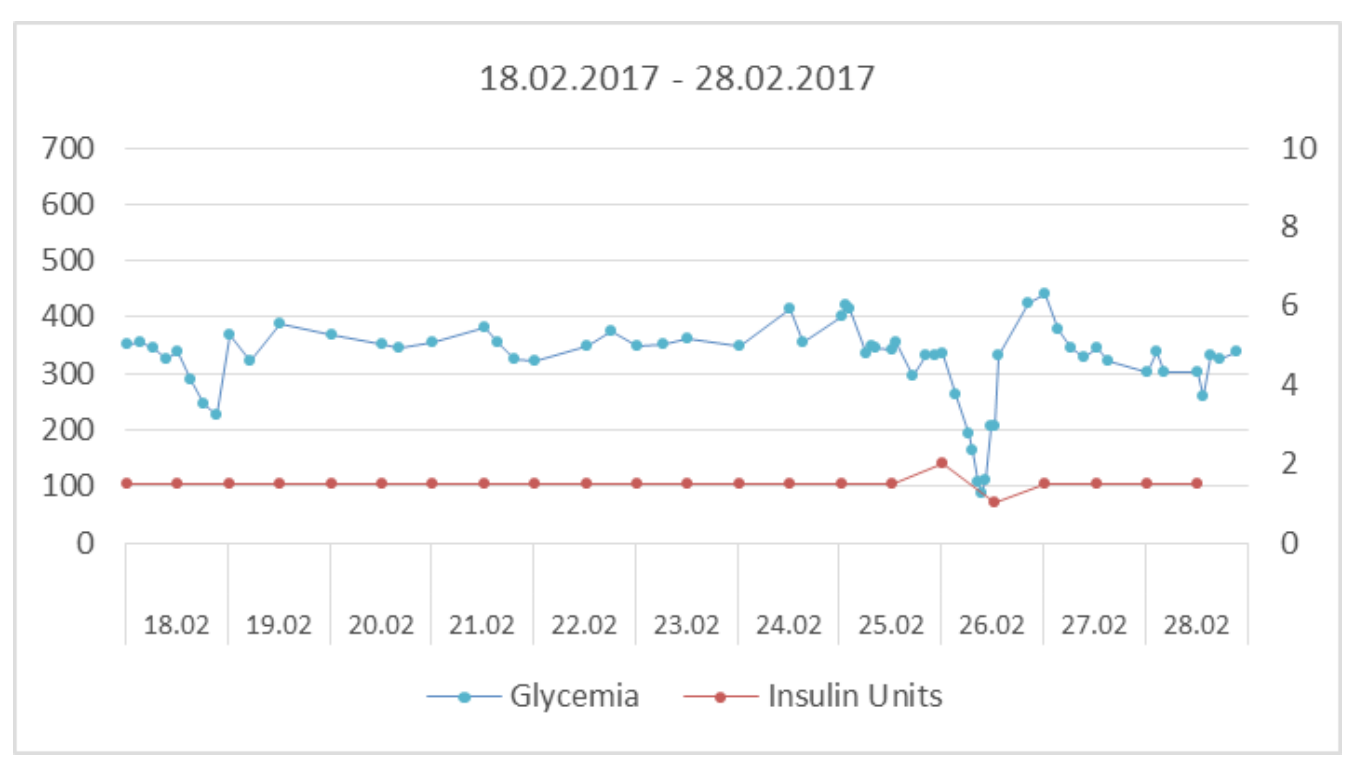

Fig. 2. Glycemia values mainly in $300-400 \mathrm{mg} / \mathrm{dL}$ zone 
Of the cases that came into remission, we present case number 9, a sterilized male, 6 years old at diagnosis and $5 \mathrm{~kg}$ weight, the date of diagnosis being February 2017. After diagnosis, the cat started the treatment with Lantus insulin, and the diet within the first 5 days after diagnosis was dry food with approx. 30\% carbohydrates, and then switched to wet food for diabetic cats with $16.3 \%$ carbohydrates (Fig. 2).

From March the $10^{\text {th }}$, he is passed on wet food with less than $10 \%$ carbohydrates, figure 3 . Very unstable glycemic curve until 08.03. when it starts to adjust. On 09.03 it has a very high spike of over $400 \mathrm{mg} / \mathrm{dl}$, and thereafter the values decrease in the desired area below $120 \mathrm{mg} / \mathrm{dl}$. Very good glycaemic curve. On March 12 he enters remission. It is a clear example of a cat diagnosed on time, fasttailed food and the right insulin. Of the regulated glycaemic cats, case number 8 , represented by a sterilized tomcat that at the time of diagnosis (07.10.2016) was 13 years of age and weighing 7 $\mathrm{kg}$. The cat has chronic renal failure for many years, and when presented to the veterinarian in 2016, he was also diagnosed with pancreatitis. After diagnosis of diabetes, Lantus insulin treatment was initiated, and the owner wanted to try the dry diet for cats with renal insufficiency which he used until 12.10, figure 4.

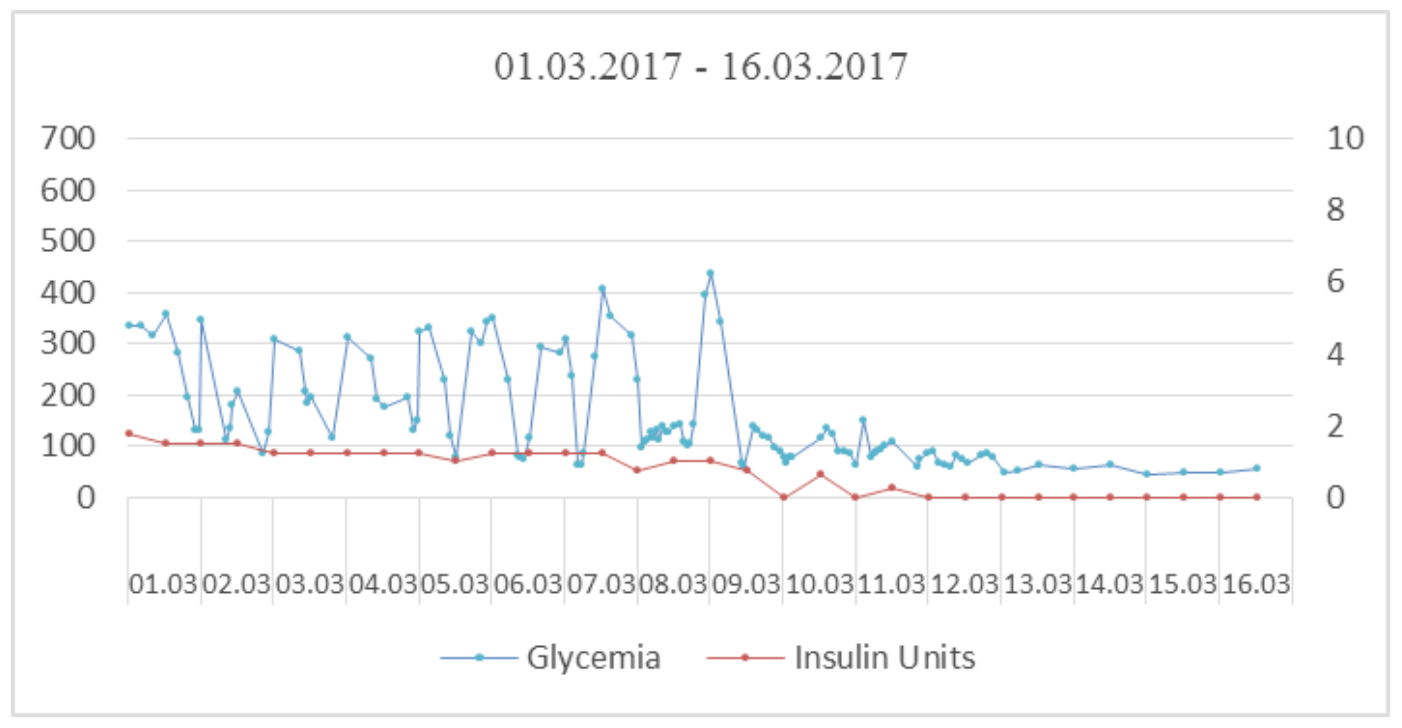

Fig. 3. Dynamics of glycemic normalization

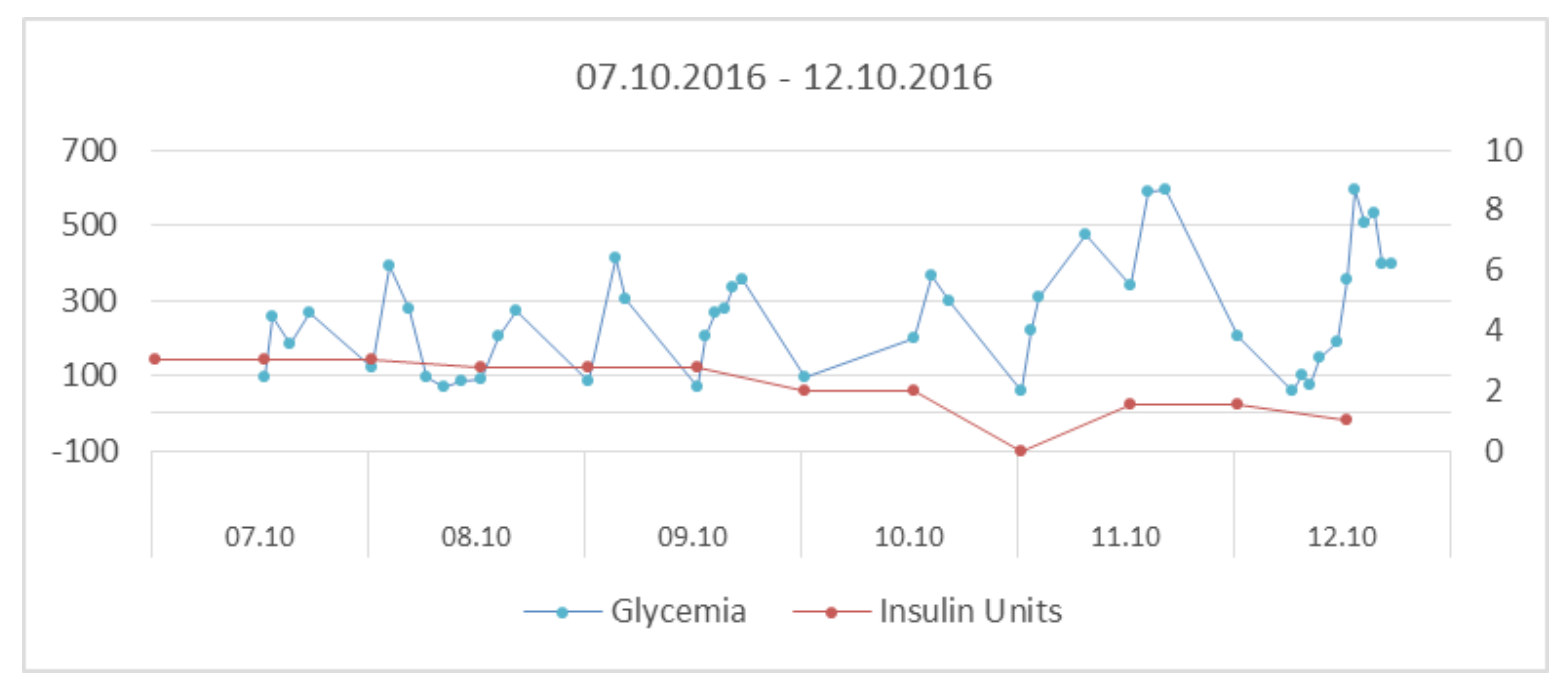

Fig. 4. Various glycemic values with many spikes 
From 13.10. to 30.10. it is fed with $9 \%$ carbohydrate wet food. The evolution of blood glucose over a two-week period can be seen in figure 5. From December, the diet changes with food with less than 3\% carbohydrates, figure 6 .

Year 2017 is promising with stable values and decreased insulin dosage, figure 7. Blood glucose values ranging from 100 to $200 \mathrm{mg} /$ $\mathrm{dl}$ after changing food to one with less than 3\% carbohydrates, its blood sugar slowly begins to fall. Blood glucose values are not yet within physiological limits: $60 \mathrm{mg} / \mathrm{dl}-120 \mathrm{mg} / \mathrm{dl}$, but they are in the blue area of the spreadsheet with maximum values of $200 \mathrm{mg} / \mathrm{dl}$.

of the non-regulated glycaemia cats, case number 6 is a sterilized female, aged 11 years and weighing $2 \mathrm{~kg}$. The cat was diagnosed on August 23, 2016, with a high blood glucose value of 741 mg / dl. After diagnosis, the cat began treatment with ProZinc insulin and was taken on dry commercial meals with a carbohydrate content of less than $1.5 \%$ and raw meat (Fig. 8). Very high

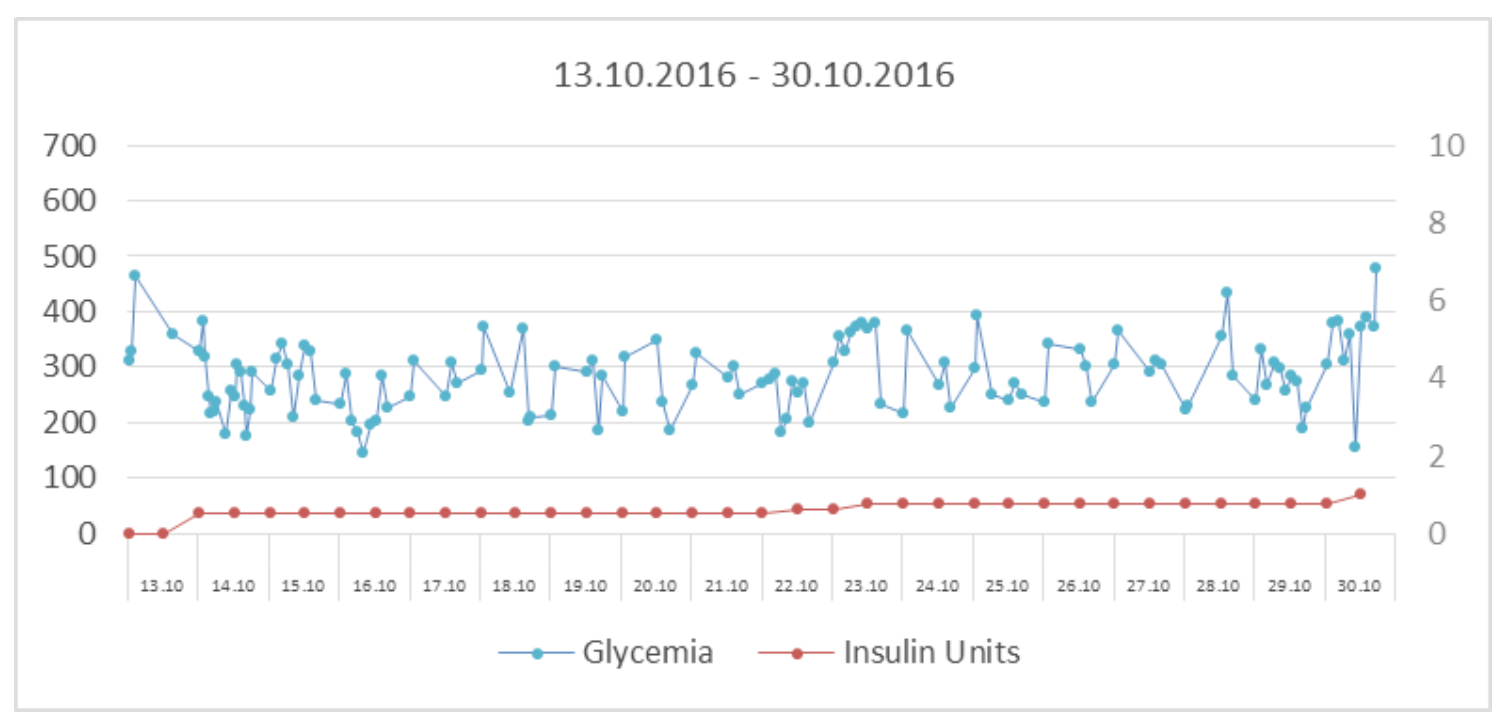

Fig. 5. Glycemic values between 200-400 mg/dL, with much less spikes

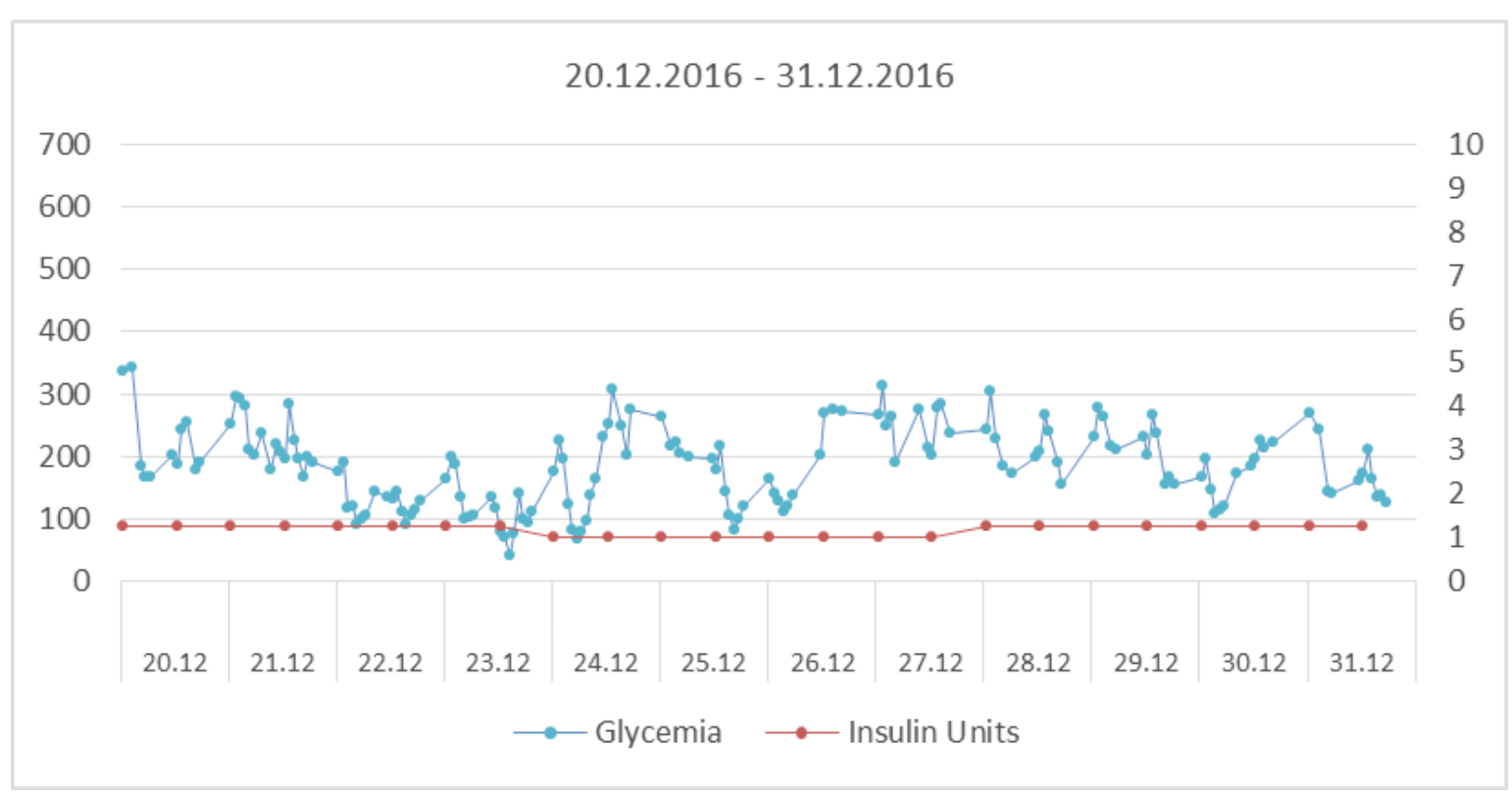

Fig. 6. Only some glycemic values in $300 \mathrm{mg} / \mathrm{dL}$ zone but glycemic curve is not yet under control 


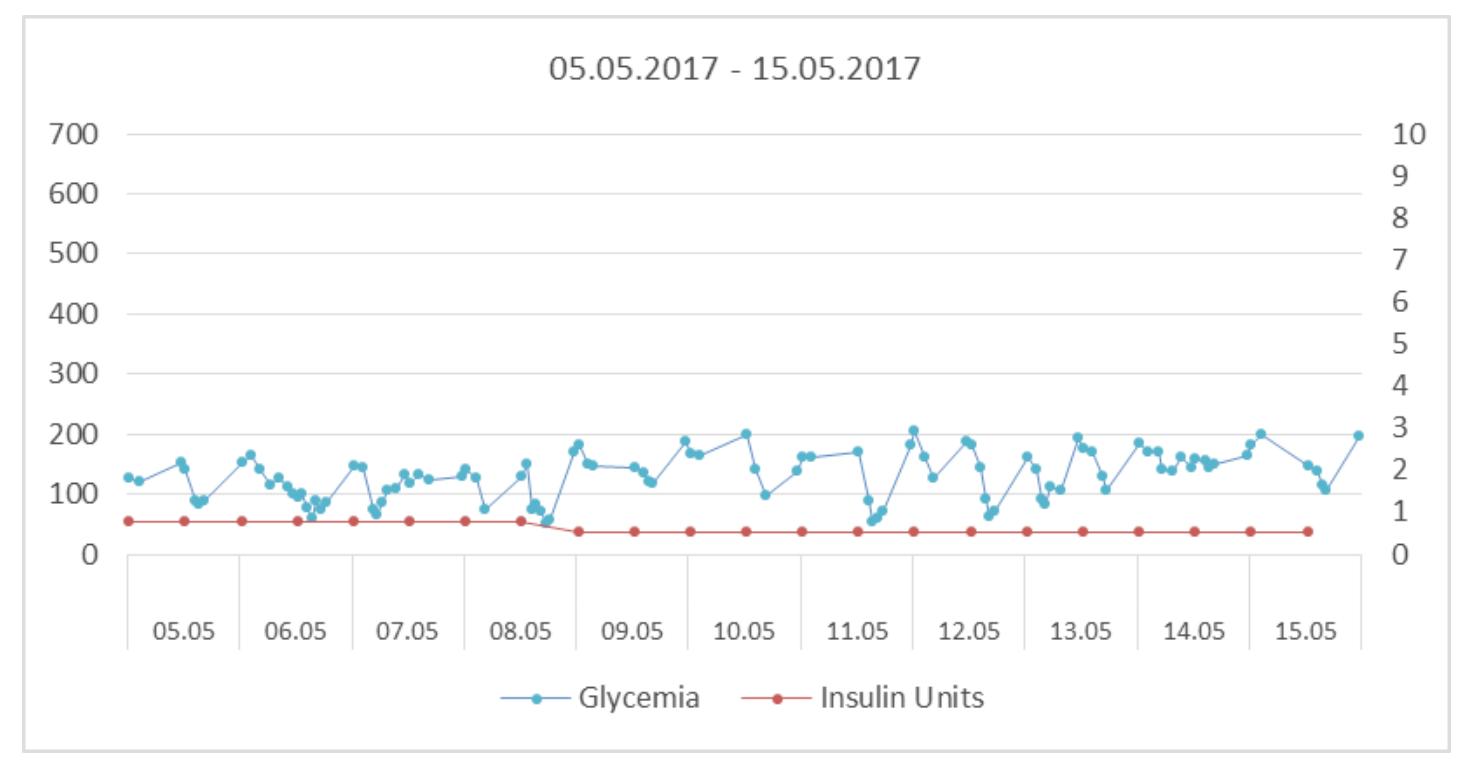

Fig. 7. Glycemic values between 100-200 mg/dL

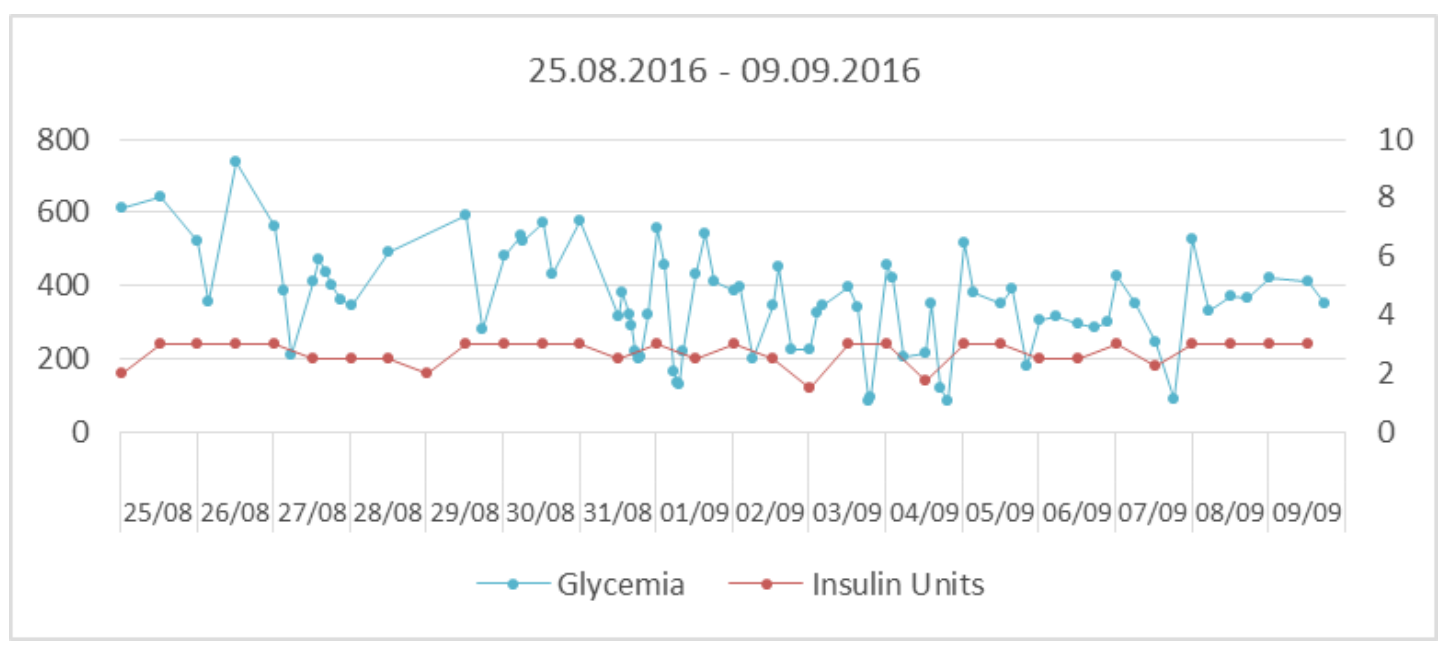

Fig. 8. Very high glycemic values, uncontrolled glycemia

blood sugar values, uncontrolled blood glucose. Due to very high blood glucose values (many days over $500 \mathrm{mg} / \mathrm{dl}$ ), it was recommended to switch to Lantus insulin, but for personal reasons, the owner refused and decided to stay on Prozinc insulin. In addition, despite high blood glucose levels, in the next period the owner decided to lower the insulin dose a lot: from 3 units, it reached 0.5 units in October 2016. In 2017 the insulin dose is slightly increased but still does not keep blood sugar under control, with very high values being recorded (Fig. 9 and Fig. 10).

Year 2017 continues to be with very high blood glucose levels, most over $400 \mathrm{mg} / \mathrm{dl}$, the only time when blood glucose starts to fall is in mid-May, figure 11. In addition to two values above $300 \mathrm{mg}$ / dl, the glycaemic curve appears to stabilize, even though the values are elevated, predominantly in the $100-200 \mathrm{mg} / \mathrm{dl}$ range. This case is quite a clear example that only a good diet is not enough for glycaemic control. The cat is hyperglycaemic for a long time due to lack of cooperation of the owner who does not want to change insulin and greatly afraid of hypoglycaemic shock and does not want to use a proper dosage of insulin recommended to blood glucose levels.

There are a lot of factors that need to be taken into account in order to lead a cat in remission: 


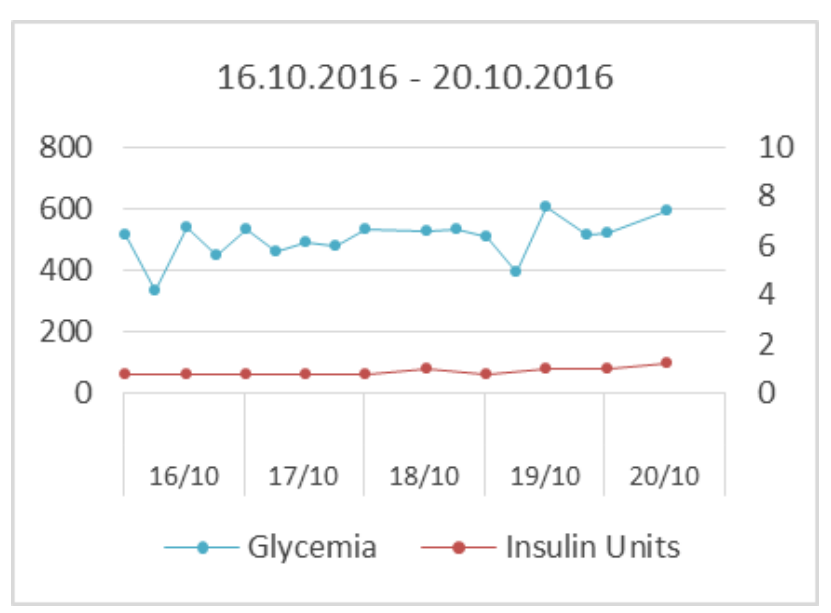

Fig. 9. Very high glycemic values, the insulin dose is very low

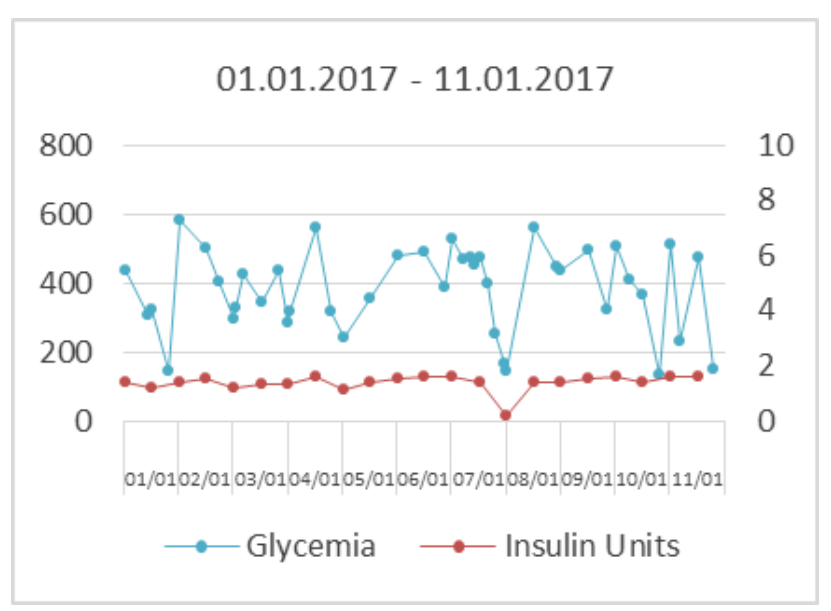

Fig. 10. The insulin dose oscillates between one unit and 1.5 units. Blood glucose is no more than $600 \mathrm{mg} / \mathrm{dL}$ but is not controlled

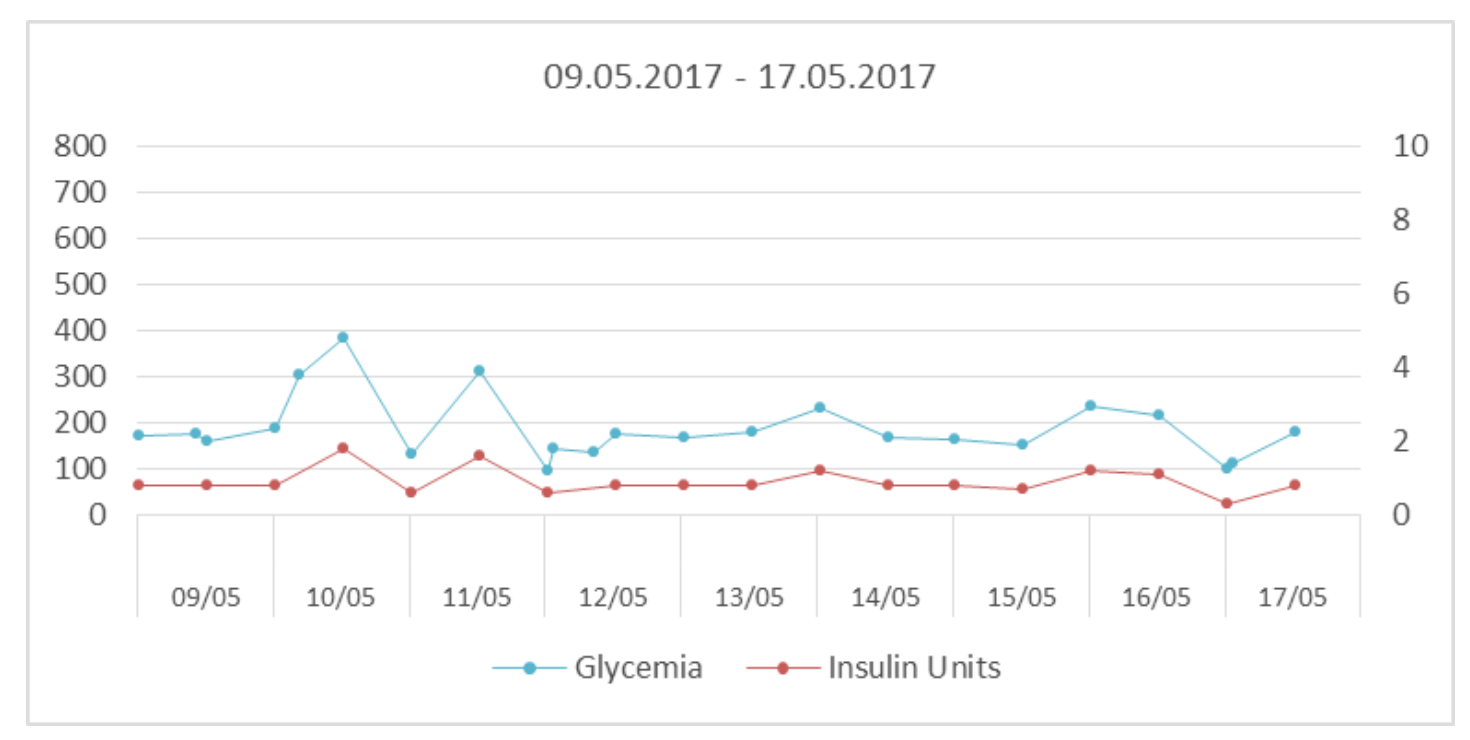

Fig. 11. Glycemic values predominantly in the $100-200 \mathrm{mg} / \mathrm{dL}$ range

- The diet: all the 4 cats who have entered the remission have done it only after they passed to a low carbohydrate diet; - Insulin: as Marshall and contributors' study said in 2009, the chances of getting into remission are greater when using Lantus insulin. This is confirmed by 3 of the cases in the study that are in remission. Of course, this does not mean that other types of insulin cannot lead to remission, for example, case number two, a sterilized female, who has entered remission using insulin Vetsulin; - Stress factors management: Because stress causes blood sugar to rise, cats diagnosed with diabetes should be as safe as possible from any stress factor. The most relevant example is case number seven, a sterilized tomcat which has high blood glucose values when it is exposed to a strong stress for it - the presence of foreign animals - for almost one year period. The hypothesis released by McCann et al. in 2007, according to which the ad libitum feeding with a diet with high protein content and low in carbohydrates, leads to the promotion of weight gain (by accruing fat tissue) and implicitly to insulin resistance development, was no confirmed by our study. All the cats included in our study lost 
weight after passing to such a diet, including the cats that have not entered remission.

\section{CONCLUSION}

Food is very important for cats. Because they are hyper carnivores, cats do not require carbohydrates in the diet, and they have the ability to procure the necessary glucose from the protein. The attending vet should take this into account especially for type II diabetic cats who can receive adequate nutrition and appropriate insulin treatment.

As a result of our study, we have come to the conclusion that it does not matter if the food is wet or dry but it matters the carbohydrate content. That is why the recommendation is for owners to check the product label, not to rely on the fact that food is for diabetic cats, because many of them have a carbohydrate content of more than $10 \%$.

\section{REFERENCES}

1. Coutto CG, Nelson RW (2014). Small animal internal medicine.Ed. Elsevier, 5:798 - 803.

2. Frank G, Anderson W, Pazak H, Hodgkins E, Ballam J, Laflamme D (2001). Use of high-protein diet in the management of feline diabetes mellitus. Veterinary Therapeutics, 2(3): 238 - 246.

3. Henson MS, O'Brien TD (2006). Feline models of type 2 diabetes mellitus. ILAR Journal, 47(3): 234 - 242.

4. Hoenig M (2002). Comparative aspects of diabetes mellitus in dogs and cats. Molecular and cellular endocrinology, 197:221 - 229.

5. Marshall RD, Rand JS, Morton JM (2009). Treatment of newly diagnosed diabetic cats with glargine insuline improves glycaemic control and results in higher probability of remission than protamine zinc and lente insulins. Journal of Feline Medicine and Surgery, 11: 683 $-691$.

6. McCann TM, Simpson KE, Shaw DJ (2007). Feline diabetes mellitus in the UK: The prevalence within an insured cat population and a questionnaire-based putative risk factor analysis. J Feline Med Surg, 9:289 - 299.

7. Nelson RW (1992). Dietary management of diabetes mellitus. Journal of Small Animal Practice, 33(5): 213 217.

8. O'Brien TD (2002). Pathogenesis of feline diabetes mellitus. Molecular and Cellular Endocrinology, 197:213 -219 .

9. Öhlund M, Egenvall A, Fall T, Hansson-Hamlin H,Röcklinsberg H, Holst BS (2017). Environmental risk factors for diabetes mellitus in cats. Journal of Veterinary Internal Medicine, 31:29- 35.

10. Rand SJ, Fleeman LM, Farrow HA, Appleton DJ, Lederer R (2004). Canine and Feline Diabetes Mellitus: Nature or Nurture. The Journal of Nutrition, 134(8):2072 - 2080.

11. Rijnberk Ad, Kooistra HS (2010). Clinical Endocrinology of Dogs and Cats. Ed. Schlütersche, 167.

12. Rotlewicz BN, Gallelli MF, Blatter MF, Miceli DD,Castillo VA (2010). Pathophysiology of diabetes mellitus and its relationship with obesity in cats. Slovenian Veterinary Research, 47:29 - 34 .

13. Rucinsky R, Cook A, Haley S, Nelson R, Zoran DL, Poundstone M (2010). AAHA diabetes management guidelines for dogs and cats. Journal of the American Animal Hospital Association, 46:215- 224.

14. Wellen KE, Hotamisligil GS (2003). Obesity-induced inflammatory changes in adipose tissue. The Journal of Clinical Investigations, 112(12): 1785-1787.

15. www.felinediabetes.com 